\title{
CONSTRUCCIÓN Y DEBATE DE UN MARCO INSTITUCIONAL FAVORABLE PARA LOS DERECHOS INDÍGENAS
}

\author{
Isabel de la Rosa Quiñones*
}

RESUMEN: La intensidad de las movilizaciones indígenas en América Latina es un elemento revelador del descontento social existente, a causa de las cada vez más menguadas condiciones de vida que enfrentan los habitantes de la región. Como un esfuerzo para evitar que esta situación se agudice, y principalmente como resultado de la presión ejercida por distintos pueblos y organizaciones indígenas, algunos organismos internacionales se han dado a la tarea de promover el desarrollo de los pueblos indígenas, inscribiendo sus actividades en el marco de la lucha por los Derechos Humanos.

Al respecto se han obtenido avances significativos en la creación de instrumentos internacionales que buscan exhortar las acciones en favor del reconocimiento, la defensa y promoción de los derechos de los pueblos indígenas. Sin embargo, como lo demuestra el caso de México, en el que no sólo el Estado desconoció un acuerdo de pacificación interno, sino también se violaron convenios internacionales adoptados y ratificados con anterioridad a la emergencia indígena de 1994, este tipo de compromisos per se no garantizan que en los hechos se registre una protección segura a los derechos colectivos de los pueblos indígenas, o que tenga lugar un mejoramiento sustantivo de sus condiciones de vida.

Palabras ClaVE: Movimientos indígenas, Pueblos indígenas, Derechos Humanos, Derechos indígenas.

ABSTRACT: The intensity of the indigenous mobilizations in Latin America is a revealing element of the existing social discontent on account of increasingly poor living conditions that inhabitants of the region have to deal with. To prevent this situation from worsening, and above all as a result of the pressure exerted by different peoples and indigenous organizations, some international bodies have been promoting the development of the indigenous peoples including their activities within the human rights fight framework. Regarding this matter, there are significant advances in the creation of international means that boost actions in favor of recognition, defense and promotion of the rights of indigenous peoples. Nevertheless, as it is

Estudiante de la Maestría en Estudios Latinoamericanos-UNAM (correodeisabel@ hotmail.com). 
shown by Mexico's case, in which not only the State did not recognize an internal pacification agreement, but also international agreements that were adopted and ratified prior to the indigenous insurgency of 1994 were violated, this kind of commitments per se does not guarantee safe protection of the indigenous peoples collective rights or a significant improvement of their living conditions.

KEY WORDS: Indigenous movements, Indigenous peoples, Human rights, Indigenous rights.

\section{INTRODUCCIÓN}

La emergencia de las movilizaciones indígenas registradas en América Latina, durante las últimas décadas, pone en entredicho la solidez de la vida democrática que las naciones de la región se esfuerzan por divulgar cotidianamente, tanto al conjunto de sus sociedades como en el ámbito internacional. ${ }^{1}$ El cuestionamiento parte de las evidencias que muestran la precariedad de las condiciones de vida que registran amplios sectores de la población, que, al negarse a ser "integrados" a los órdenes constituidos por las culturas dominantes y defender su diferencia arraigada en un abanico de identidades étnicas y desarrollos culturales propios, fueron negados históricamente, ocupando hasta la fecha los estratos más bajos de la escala social de dichos países.

El consenso sobre la fragilidad de los Estados-nación que descansan su legitimidad en discursos que afirman su formación a partir de

1 En la consideración de Águeda Gómez, por ejemplo, se destaca entre los movimientos indígenas recientes al "movimiento indígena zapatista de Chiapas (México), el alzamiento indígena en Ecuador, que precipitó la dimisión del presidente del país, las nuevas tendencias electorales en Perú, las manifestaciones indígenas en Brasil contra la celebración del descubrimiento del país por los portugueses, las movilizaciones populares en Bolivia, donde $90 \%$ de la población campesina es indígena, y la llegada al poder de un líder indígena como vicepresidente del país, el líder katarista Víctor Hugo Cárdenas en el pasado gobierno (1993-1997), y las recientes rebeliones en Guatemala", "Nuevos actores frente al fenómeno de la globalización: los movimientos indígenas en América Latina", Cuadernos Americanos, núm. 89, México, septiembre-octubre, 2001, p. 188. 
una supuesta homogeneidad cultural originaria, y, en consecuencia, el desarrollo de una identidad nacional única, es ahora un punto de crítica recurrente entre los diversos sectores sociales que evalúan el desempeño de sus principales instituciones. Sin embargo, el reconocimiento de lo insostenible que es fincar la convivencia social a partir de apariencias no ha traído aparejado, de manera inmediata, el reconocimiento social en una dimensión humana, igualitaria y justa de quienes han sido objeto de negación y exterminio.

De modo específico, en el caso de los pueblos indígenas ${ }^{2}$ que se autorreconocen como los herederos legítimos de los pobladores originarios de la región, el camino recorrido desde su exterminio, dominación, explotación y negación, hasta su precario reconocimiento como grupos cultural y socialmente diferenciados, ha sido particularmente largo y difícil. Ello se comprueba en la falta de voluntad política de quienes, al contar con capacidad de decisión e incidencia en el conjunto de las sociedades de las que éstos forman parte, se niegan a emprender medidas que en los hechos puedan modificar las condiciones estructurales (económicas, sociales y culturales) que han perpetuado las circunstancias de desigualdad y marginación, en las que hasta hoy sobreviven los indígenas.

2 Al referirnos a "indígenas" y "pueblos indígenas o indios" retomamos las definiciones propuestas en un estudio realizado por la Subcomisión de Prevención de Discriminaciones y de Protección a las Minorías de la ONU que especifica: "Son comunidades, pueblos y naciones indígenas los que, teniendo una continuidad histórica con las sociedades anteriores a la invasión y precoloniales se desarrollaron en sus territorios, se consideran distintos de otros sectores de las sociedades que ahora prevalecen en esos territorios o en partes de ellos. Constituyen ahora sectores no dominantes de la sociedad y tienen la determinación de preservar, desarrollar y transmitir a futuras generaciones sus territorios ancestrales y su identidad étnica como base de su existencia continuada como pueblo, de acuerdo con sus propios patrones culturales, sus instituciones sociales y sus sistemas legales [...] Desde el punto de vista individual, se entiende por persona indígena toda persona que pertenece a esas poblaciones indígenas por autoidentificación como tal indígena (conciencia de grupo) y es reconocida y aceptada por esas poblaciones como uno de sus miembros (aceptación por el grupo)". Citado por Rodolfo Stavenhagen en Derecho indigena y derechos humanos en América Latina, México, COLMEX-IIDH, 1988, pp. 137 y 138. 
Aunado a lo anterior, en la actualidad prevalecen corrientes de pensamiento de esencia positivista, que sostienen una visión evolutiva de la historia, misma que al argumentar a favor de la "modernidad" como único fin posible y deseable para nuestras sociedades, rechaza cualquier intento emprendido con el objeto de atender las principales necesidades de la población india, argumentando que sus demandas sólo pueden ser interpretadas como rasgos anacrónicos de un pasado que se resiste a desaparecer, y que, por tanto, al fomentarlo remitiría a mayores atrasos en el camino hacia el tan ansiado "desarrollo".

A pesar de este contexto en extremo impositivo, la intensidad de las luchas emprendidas por estos actores y la continuidad de las mismas ha permitido que algunas de sus principales preocupaciones hayan tenido resonancia en instancias supranacionales, que al haber sido creadas entre otros fines con el objeto de mediar y conciliar los conflictos entre naciones o al interior de éstas, y para promover el desarrollo de la condición humana en todos los ámbitos, cuentan con un compromiso de facto con los grupos vulnerables.

Esta preocupación originaria, convertida hoy en obligación moral como respuesta a la presión social reiteradamente ejercida por las movilizaciones indígenas en gran parte de Latinoamérica, ha permitido que instancias internacionales como la Organización Internacional del Trabajo (OIT), la Organización de las Naciones Unidas (ONU), a través de comisiones específicas y de órganos como la Organización de las Naciones Unidas para la Educación, la Ciencia y la Cultura (UNESCO), y la Organización de Estados Americanos (OEA), en la actualidad consideren la importancia de promover que los indígenas sean escuchados y tratados en un marco de respeto e igualdad de oportunidades dentro de las sociedades a que pertenecen.

El eje del compromiso básico que relaciona a las instituciones mencionadas con los grupos indígenas y sus luchas, se articula en torno a la defensa de los Derechos Humanos que da razón y sentido de ser a sus actividades. Así, el interés por acompañar y difundir las preocupaciones de los indígenas resulta una tarea ineludible para aquellas entida- 
des que desde su fundación se proclamaron como las principales promotoras de la condición humana y el desarrollo de sus potenciales, tanto individuales como colectivos.

Sin embargo, este camino tampoco se ha encontrado libre de obstáculos y retrocesos, dado el carácter de las principales demandas que los indígenas, sus comunidades, pueblos y organizaciones vienen señalando con mayor intensidad y claridad política en los últimos años. A saber, plantean su reconocimiento inicial y esencial como pueblos, es decir, como "sujetos de derechos colectivos"; también se exige la reivindicación de sus derechos de "propiedad sobre los territorios" que ocupan o de los que han sido despojados; se busca el derecho al autogobierno y la "autonomía" que, en una concepción más compleja, que a la vez incluye a las otras demandas, se articula como el "derecho a la autodeterminación"; se exige justicia social en su sentido más amplio; hasta, finalmente, proponer pasar de una noción de "universalidad" (homogeneizante) a una de "multiculturalidad", tanto en lo relativo a la definición y defensa de los Derechos Humanos, como también en el orden y la organización misma de las sociedades.

Como es evidente, tales demandas no sólo se enfrentan a la presencia de condiciones estructurales que dificultarían el cumplimiento de sus planteamientos, sino que, básicamente, al implicar la realización de cambios profundos en el conjunto de las sociedades se contrapone, principalmente, con los intereses de las minorías dominantes a escala mundial, que resultan beneficiadas con la situación prevaleciente. Así pues, como se ha dicho, el problema no sólo es estructural (social y económico), sino que básicamente es político e ideológico, llevándonos en última instancia a pensar en él en términos de luchas entre un poder dominante y el poder popular de los dominados, mismas que, según las dinámicas que registren, permiten en ocasiones establecer algunos contrapesos a la impunidad de los primeros, pero difícilmente parecen afectar en su totalidad a los elementos que cimientan su posición.

Dentro de los principales "contrapesos" que actualmente cuentan con mayor influencia a escala internacional, se encuentra la defensa de 
los Derechos Humanos, que sirve como marco para promover la atención hacia los principales problemas que enfrentan los grupos marginados. En esta preocupación se han canalizado esfuerzos para profundizar conceptualmente sobre la necesidad de ampliar los tipos de derechos reconocidos universalmente, así como el contenido mínimo de éstos. Fundamentalmente, el avance más importante en este rubro es el reconocimiento de la "indivisibilidad" e "interdependencia" de los derechos civiles y políticos, y de los derechos económicos, sociales y culturales (DESC), ${ }^{3}$ al lograr constituir con ello el fortalecimiento de una serie de garantías individuales y colectivas. ${ }^{4}$

La aparente incompatibilidad entre intereses individuales y colectivos, que pudiera presentarse en lo formal, se resuelve a través del planteamiento sobre las características fundamentales compartidas por ambos grupos de derechos: universalidad, indivisibilidad, inalienabilidad e interdependencia. ${ }^{5}$ Mismas que en suma permiten sostener que

3 En un planteamiento general los DESC comprenden: el derecho a la libre determinación, el derecho a un nivel de vida adecuado, el derecho a una alimentación adecuada, el derecho a la vivienda adecuada, el derecho a la salud (que incluye el derecho a un medio ambiente sano), el derecho a la protección y asistencia a la familia, el derecho a la educación, los derechos culturales, los derechos humanos laborales (al trabajo, a condiciones equitativas y satisfactorias de trabajo, a fundar y afiliarse a sindicatos, libertad sindical y huelga, a la seguridad social), y el principio de igualdad de derechos de hombres y mujeres. Véase Areli Sandoval Terán, Los derechos económicos, sociales y culturales. Una revisión del contenido esencial de cada derecho y de las obligaciones del Estado, México, DECA Equipo Pueblo, A.C.-Asociación Latinoamericana de Organizaciones de Promoción, 2001, 96 pp.

${ }^{4}$ Es preciso señalar que frente a la comprensión tradicional que distingue a los derechos civiles y políticos, por su orientación individualista, de los DESC, a los que comprende como derechos de orden colectivo, es necesario reconocer que esta diferenciación no opera como tal en sentido estricto. Así, mientras que dentro de los primeros se pueden encontrar derechos enunciados que, si bien pueden ser reivindicados por un individuo, es evidente que para su ejercicio pleno sólo pueden ser realizados como tales por una colectividad (por ejemplo: el derecho de asociación o el derecho a la información), en lo que respecta a los DESC, aunque los derechos que comprenden pueden ser considerados como colectivos, es necesario reconocer que los destinatarios a los que van dirigidos siguen siendo personas consideradas a título individual.

5 En una exposición sencilla Areli Sandoval Terán define cada una de estas características: "Los derechos económicos, sociales y culturales (DESC) son derechos 
no se puede lograr el pleno goce de un grupo de derechos (los civiles y políticos), si los del otro grupo no se encuentran satisfechos (IOS DESC).

No obstante que este argumento resulta sólido, debido a la explicación lógica que ofrece y a la propia racionalidad con que se les concibe a los Derechos Humanos, su enunciación es el origen de la principal controversia y reserva de los Estados-nación con respecto a la suscripción de los compromisos multilaterales, que en algún modo les obligaría a respetar literalmente esta concepción.

Lo anterior se explica a raíz de que, en el contexto actual donde predomina el interés de la economía globalizada, una lectura de los derechos civiles y políticos sugiere que su promoción puede tener sentido en función de un interés esencial en el principio de protección de la propiedad (privada), misma que constituye el punto nodal del sistema de producción y organización social vigente, mientras que la observancia de los DESC en su sentido colectivo implicaría - dado el caso- el reordenamiento de la propiedad en función de poder garantizar las condiciones mínimas de existencia a quienes menos tienen. En consecuencia, según esta interpretación, es entendible por qué los beneficiados con el estado actual de las cosas unen sus esfuerzos y ejercen presión sobre los representantes de los estados, para oponerse a estos planteamientos.

Una experiencia ejemplar al respecto la podemos observar a partir del caso registrado durante los últimos años en México, donde la controversia generada a causa de la negativa estatal a reconocer los derechos colectivos de los pueblos indios que habitan en "su territorio", mismos que habían sido pactados como acuerdos iniciales ${ }^{6}$ para disten-

humanos, y como tales, tienen su origen en la dignidad inherente a todas las personas, por lo que son: a) universales (pertenecen a todo ser humano); b) indivisibles (no pueden fraccionarse ni reducirse); c) inalienables (no se pueden perder), y d) interdependientes (la realización de cada derecho es indispensable para el pleno goce de los demás derechos)". Cfr., op. cit., p. 13.

${ }^{6}$ Me refiero al los Acuerdos sobre Derechos y Cultura Indígena, firmados el 16 de febrero de 1996 en el municipio de San Andrés Larráinzar, Chiapas. 
der una movilización promovida por el Ejército Zapatista de Liberación Nacional (EZLN), que reivindicaba demandas indígenas, y que en consecuencia llevaron a los gobiernos en turno a desconocer las obligaciones que en un sentido similar (observancia y promoción de los DESC y reconocimiento y respeto de los pueblos indios) habían suscrito y ratificado con anterioridad con organismos internacionales como la ONU y la OIT.

Los siguientes apartados pretenden reflexionar en torno a los argumentos presentados por el Estado, representado por el Gobierno Federal, y los pueblos indígenas, representados por quienes participaron en la negociación de los Acuerdos de San Andrés, tanto a favor como en contra del reconocimiento de los derechos de autodeterminación y autonomía a estos grupos sociales, utilizando como marco de referencia lo que dicen algunos de los principales instrumentos internacionales que tratan sobre estos derechos, elaborados en el seno de organizaciones que se preocupan por la situación de los indígenas, y que en este interés han hecho de los Derechos Humanos su espacio de acción para ayudar a resolver esta clase de conflictos.

\section{EL MARCO INTERNACIONAL FAVORABLE A LOS DERECHOS INDÍGENAS}

A partir de una revisión inicial sobre el desarrollo de los instrumentos internacionales que en algún modo abogan por el reconocimiento y respeto de la integridad de los grupos indígenas, tanto en niveles intranacionales como en el plano mundial, en principio se puede observar que dichas herramientas tienen sus orígenes a partir de dos grandes rubros: el derecho internacional público y el derecho de los Derechos Humanos. ${ }^{7}$

Mientras que el primero básicamente se ha ocupado de las relaciones exteriores entabladas entre estados, en el segundo campo es donde se han registrado mayores avances en lo tocante al reconocimiento de los derechos inherentes a las colectividades humanas que, no obstante

7 Cfr. Rodolfo Stavenhagen, "El marco internacional del derecho indígena", en Magdalena Gómez [coord.], Derecho Indígena, México, INI-AMNU, 1997, p. 43. 
pertenecer formalmente al conjunto de una nación, en los hechos viven y se conciben como grupos diferenciados cultural y socialmente, que — sin importar su condición numérica en términos de población (como minorías o como mayorías no reconocidas) — buscan ser reconocidos desde su particularidad y tratados con igualdad.

Si bien es preciso reconocer que el marco de los Derechos Humanos no es suficiente para lograr resolver la diversidad de problemas que han enfrentado los pueblos indígenas en Latinoamérica, desde la "conquista" de sus territorios hasta la actualidad, es necesario señalar que el constante trabajo desarrollado en este ámbito ha permitido cimentar un aparato de presión internacional contra quienes atentan en cualquier forma a la dignidad de estos grupos, ya sea de manera directa o indirecta. No son poca cosa estos señalamientos, cuando prevalece una época marcada por la interdependencia económica y política, donde los estados se ven obligados a mantener una imagen pública internacional favorable a lo que eufemísticamente se ha denominado como "políticamente correcto".

Lo anterior plantea una lectura crítica de los instrumentos de sanción que en este sentido ofrecen organismos internacionales como la ONU, la OIT y la OEA, advirtiendo que, si bien las principales trabas para la aprobación de convenios y declaraciones que resultan indispensables para avanzar en el reconocimiento de los derechos indígenas son de índole política, ${ }^{8}$ por otro lado, también debe tomarse conciencia de la opor-

8 Al respecto Rodolfo Stavenhagen señala que: "si bien algunos de los citados instrumentos internacionales solamente tienen valor moral y político, mientras que otros (Convenios ratificados por los Estados miembros) sí tienen fuerza vinculatoria y jurídica, cuando menos formalmente, el problema de fondo siguen siendo los procedimientos para que estos tratados sean cumplidos efectivamente. Ni la Organización de las Naciones Unidas ni los organismos regionales tales como la Organización de los Estados Americanos, están dotados de mecanismos que obliguen a los Estados a cumplir con sus compromisos internacionales. En otras palabras, los países que no quieren cumplir con los compromisos asumidos y ratificados, pueden hacerlo impunemente. Es por ello que también se han hecho intentos en la ONU para dotar a los textos jurídicos aprobados de mecanismos institucionales que tengan alguna efectividad, aunque sea mínima", en "El marco...", p. 50. 
tunidad que ofrecen estos espacios para la acción y la denuncia en contra de las violaciones cometidas a este respecto.

\section{a) La Organización de las Naciones Unidas}

Desde su fundación, en el seno de la ONU ha existido una preocupación fundamental por proteger a quienes, por su condición social o cualquier afirmación de su particularidad, se encuentran en posición de desventaja con respecto al conjunto de sus sociedades. Sin embargo, los primeros instrumentos desarrollados por esta instancia a efecto de corregir dicha situación contaron con una limitación básica, originada en su propia articulación a partir de premisas individualistas, considerándose así documentos fundamentales como la Declaración Universal de los Derechos Humanos proclamada en 1948.

Para el caso de los derechos indígenas, la afirmación de la igualdad contenida en esta declaración fue acogida con un doble significado: por un lado se le entendió como una posibilidad para exigir el derecho a un trato no discriminatorio para los indígenas, y, por otro, se le criticó por negar la particularidad sociocultural de sus pueblos, la que, dadas las condiciones de desarrollo histórico desigual, obliga a otorgar un trato distinto hacia estos pobladores, al reconocer que dicha igualdad jurídica no ha tenido su correlato en el acceso equitativo a otro tipo de oportunidades.

Con el objeto de precisar y procurar un mayor compromiso de los Estados-parte con relación a los derechos establecidos en la Declaración Universal, suscritos por ellos, en 1966 la ONU adoptó dos convenios internacionales que plantearon un desarrollo conceptual de éstos, el Pacto Internacional de Derechos Civiles y Políticos (PIDCyP) y el Pacto Internacional de Derechos Económicos, Sociales y Culturales (PIDESC), de los cuales llama la atención el reconocimiento del derecho a la libre deter- 
minación de los pueblos enunciado desde los primeros párrafos del artículo $1^{\circ}$ (idéntico en ambos pactos), en el que se establece que

Todos los pueblos tienen el derecho a la libre determinación. En virtud de este derecho establecen libremente su condición política y proveen asimismo a su desarrollo económico, social y cultural. Para el logro de sus fines, todos los pueblos pueden disponer libremente de sus riquezas y recursos naturales, sin prejuicio de las obligaciones que derivan de la cooperación económica internacional basada en el principio del beneficio recíproco, así como del derecho internacional. En ningún caso podrá privarse a un pueblo de sus propios medios de subsistencia [...]. ${ }^{9}$

A partir de la enunciación del derecho de los pueblos se observa un avance que redimensiona la importancia de los derechos colectivos al mismo nivel de los derechos de carácter individual, subrayando la necesidad básica de su satisfacción para poder asegurar el cumplimiento pleno de todos los demás derechos.

En lo relativo a los derechos indígenas, el reconocimiento de los DESC como derechos esencialmente colectivos proporcionó mayores instrumentos para la defensa de las demandas que, como pueblos originarios, los indígenas expresaban a sus instituciones públicas y sociedades locales. Ello no obstante la ambigüedad básica referida a la indefinición del concepto de "pueblos" por parte de la ONU, elemento que ha sido uno de los principales obstáculos para lograr la exigibilidad plena de dichos derechos. ${ }^{10}$

Tras la adopción y ratificación que los Estados-parte han hecho de los pactos adoptados por la ONU, este organismo ha desarrollado instrumentos más específicos que apuntan en la misma dirección de defender los derechos colectivos. Dichos acuerdos y declaraciones descansan en

9 PIDESC, artículo $1^{\circ}$, párrafos 1 y 2, citado por Sandoval Terán, op. cit., p. 29.

${ }^{10} \mathrm{Al}$ respecto, cabe aclarar que si bien al inicio de este trabajo se cita una definición de "pueblos indígenas" elaborada en el marco de un proyecto de investigación auspiciado por la ONU, ello no implicó que este organismo haya adoptado oficialmente ese contenido del término, de ahí que aquí se señale su ambigüedad cuando se refiere a estas colectividades con un concepto que no llega a explicitarse de manera formal en sus documentos de trabajo. 
dos principios fundamentales para este organismo: "la igualdad entre todos los seres humanos y la no discriminación en contra de cualquier persona por motivos raciales, culturales, religiosos u otros". ${ }^{11}$ Así es como el conjunto de acciones tomadas en torno al derecho de las minorías nacionales o étnicas, religiosas y lingüísticas ha servido en primera instancia para apoyar el ejercicio de los derechos humanos de los pueblos indígenas, aunque también es preciso reconocer que ello sólo procede cuando éstos son identificados como minorías, siendo inviable su argumentación para aquellos pueblos indígenas que, no obstante ser negados como tales por los Estados-nación a que pertenecen, constituyen la mayor parte de su población. Al respecto, los propios pueblos indígenas han expresado su negativa a ser tratados como minorías, sin importar su condición numérica, ya que esto desdibuja su preocupación esencial: la discriminación de que son objeto en sus sociedades. Así, sus principales demandas se orientan mayoritariamente por el principio de no discriminación reivindicado por Naciones Unidas.

En consecuencia, la promoción de los derechos indígenas se ha apoyado con mayor peso en el derecho a la libre autodeterminación reconocido por este organismo. A raíz de las controversias que ha suscitado este instrumento, la ONU ha canalizado el tratamiento de estos asuntos a distintas instancias que, para 1981, cristalizaron en la creación de un Grupo de Trabajo sobre Poblaciones Indígenas, dependiente de la Subcomisión de Prevención de Discriminaciones y Protección a las Minorías, mismo que tras trabajos de diagnóstico sobre los problemas que enfrentan los indígenas y la consulta sobre éstos con representantes de ellos, actualmente trabaja en la elaboración de una Declaración de los Derechos de los Pueblos Indígenas, que deberá ser adoptada por la Asamblea Nacional de Naciones Unidas. Sin bien, aun en el caso de que el punto que genera mayor inquietud (la autodeterminación) sea suscrito a favor de los pueblos indios por la ONU, también existe la conciencia al respecto de que esto no bastará para que los Estados-parte adopten y lle-

11 Stavenhagen, "El marco..., p. 51. 
ven a efecto los postulados de dicha declaración, por lo que se vislumbra como absolutamente necesaria una participación social amplia en la exigencia del reconocimiento y la justiciabilidad ${ }^{12}$ de dichos derechos por parte de los gobiernos locales.

\section{b) La Organización Internacional del Trabajo}

Sin duda, uno de los organismos multilaterales que más rápidamente ha avanzado en el reconocimiento de los derechos colectivos y en específico de los pueblos indios es la OIT. Tras una preocupación inicial sobre estos asuntos planteada en 1957, con la adopción del Convenio 107 que proponía la protección de las poblaciones indígenas y tribales en países independientes desde una perspectiva paternalista e integracionista por parte de los Estados-nación, se impulsó una revisión de éste promovida por las amplias críticas que señalaban la continuidad de un espíritu colonialista respecto a la manera de concebir estas cuestiones, la cual dio como resultado la adopción en 1989 del Convenio 169 por la Conferencia General de este organismo, constituyéndose así en el primer (y único hasta la fecha) "instrumento jurídico internacional sobre los derechos humanos de los pueblos indígenas". ${ }^{13}$

En lo tocante al derecho a la libre autodeterminación de los pueblos, en distintos apartados (artículos 7, 14, 15, 16, 17 y 18) se toca este tema, destacando lo contenido en el artículo $7^{\circ}$ de este convenio, que declara

1. Los pueblos interesados deberán tener el derecho a decidir sus propias prioridades en lo que atañe al proceso de desarrollo, en la medida que éste afecte a sus vidas, creencias, instituciones y bienestar espiritual y a las tierras que ocupan o utilizan de alguna manera, y de controlar, en la medida de lo posible, su propio desarrollo económico, social y cultural. Además, dichos pueblos deberán participar en la formulación, aplicación y evaluación

12 Por "justiciabilidad" nos referimos a la exigibilidad de los Derechos Humanos traducida "[...] (en un) proceso legal o exigibilidad jurídica [...] (misma que) implica (la) defensa de derechos violados ante tribunales o instancias administrativas adecuadas". Sandoval Terán, op. cit., p. 27.

13 Stavenhagen, "El marco..., p. 62. 
de los planes y programas de desarrollo nacional y regional susceptibles de afectarles directamente. ${ }^{14}$

Sin embargo, la definición misma que hace la OIT de los pueblos indígenas se considera como el aspecto más trascendente de este convenio, estableciéndose en el artículo $1^{\circ}$, inciso $b$, cuando se refiere a los sujetos a quienes se aplica el convenio:

b) a los pueblos en países independientes, considerados indígenas por el hecho de descender de poblaciones que habitaban en el país o en una región geográfica a la que pertenece el país en la época de la Conquista o la Colonización o del establecimiento de las actuales fronteras estatales y que, cualquiera que sea su situación jurídica, conservan todas sus propias instituciones sociales, económicas, culturales y políticas, o parte de ellas.

2. La conciencia de su identidad indígena o tribal deberá considerarse un criterio fundamental para determinar los grupos a los que se aplican las disposiciones del presente convenio.

3. La utilización del término "pueblos" en este convenio no deberá interpretarse en el sentido de que tenga implicación alguna en lo que atañe a los derechos que pueda conferirse a dicho término en el derecho internacional. ${ }^{15}$

Como lo señala Francisco López Bárcenas, con el reconocimiento de la existencia de pueblos indígenas dentro de los países independientes, en el convenio se da un avance importante con relación a otros instrumentos internacionales orientados en este sentido, ya que se admite de facto que la población de un Estado puede estar integrada por individuos y por pueblos, estableciendo en consecuencia una clara diferenciación entre "Estado" y "pueblo", en donde al primero se le identifica como a una entidad soberana y persona jurídica de derecho internacional, y a los segundos como parte de la población de un Estado-nación que "por

14 OIT, Convenio núm. 169 Sobre Pueblos Indígenas y Tribales, 1989, citado por Sandoval Terán, op. cit., p. 31.

15 OIT, Convenio núm. 169 Sobre Pueblos Indigenas y Tribales, 1989, citado por Francisco López Bárcenas, Autonomía y derechos indígenas en México, México, CONACUlTA-Centro de Orientación y Asesoría a Pueblos Indígenas, 2002, p. 30. 
sus características históricas y culturales específicas son titulares, colectivamente, de ciertos derechos que el resto de la población no posee, sin los cuales no pueden ejercer plenamente los derechos individuales reconocidos al resto de la población del Estado que forman parte". ${ }^{16}$

\section{c) La Organización de Estados Americanos}

En lo que corresponde a la OEA, no obstante que su área de influencia es más limitada, al tratarse de un organismo de carácter continental, y a que sus trabajos en esta materia son relativamente recientes, es preciso destacar la labor que ha venido realizando en la promoción de los Derechos Humanos en el plano del derecho internacional.

Desde sus inicios, al adoptar en 1948 la Declaración Americana de los Derechos del Hombre y al mismo tiempo presentar la Carta de la Organización de los Estados Americanos (que entraría en vigencia en 1951), en el marco de la IX Conferencia Interamericana, realizada en Bogotá, Colombia, la OEA ha propuesto una serie de instrumentos legales para la protección de los Derechos Humanos en la región que no sólo han innovado la normatividad existente, sino que — apoyándose en las distintas actividades que desarrollan los órganos que la integran (la Asamblea General, el Consejo Permanente y la Comisión Interamericana de Derechos Humanos) - ha logrado ampliar algunos de los planteamientos sobre este tema elaborados desde otras instancias. Tal fue el caso en materia de derechos indígenas, cuando el proyecto de Declaración Americana sobre los Derechos de los Pueblos Indígenas, presentado en 1997 por la CIDH, no sólo actualizó algunos de los términos utilizados en el Convenio 169 de la OIT, sino que también incorporó una propuesta de regulación de la propiedad intelectual sobre creaciones originales generadas por los pueblos indígenas. ${ }^{17}$

16 Loc. cit.

17 Cletus Gregor Barié señala que en esta nueva declaración es cuando se habla por primera vez de "filosofía y concepciones lógicas" indígenas en lugar de las "aspiraciones 
Sumado a lo anterior, en la actualidad la OEA se ha dado a la tarea de promover una política indigenista entre los Estados de la región ${ }^{18}$ que, a través del Instituto Indigenista Interamericano, busca desarrollar un instrumental jurídico sobre los derechos de los pueblos indígenas americanos.

\section{Debate actual sobre los Derechos IndíGenas en MÉXico}

El reclamo de los pueblos indígenas de México por el reconocimiento de sus derechos colectivos ha sido una constante a lo largo de la historia del país, desde su constitución como Estado-nación independiente. Lo anterior puede comprobarse con la permanencia de las luchas sostenidas por estos grupos sociales, mediante las que su rebeldía ha sido el conducto para expresar su negativa a ser "integrados" o asimilados a una cultura que les ha exigido desprenderse de sus identidades y desarrollos culturales propios. Sin embargo, con la emergencia indígena articulada en un frente amplio a partir del levantamiento armado promovido por el EZLN en el estado de Chiapas el primer día de 1994, estas demandas han cobrado mayor difusión en el conjunto de la sociedad.

Los resultados de este proceso han permitido que la denominada "agenda indígena" lograra obtener un lugar central en la política nacional, mismo que históricamente le fue negado mediante argumentos discriminatorios, que consideraban a lo indígena como parte de un pasado muerto o como meros referentes folclóricos en el mejor de los casos.

y formas de vida" que manejaba el Convenio 169, asimismo se utiliza la expresión "derecho indígena" dejando atrás la de "derecho consuetudinario". Finalmente, una innovación importante que destaca este autor es el planteamiento sobre el copyright de las creaciones indígenas. Cfr., Pueblos indigenas y derechos constitucionales en América Latina: un panorama, México, Instituto Indigenista Interamericano, 2000, p. 87.

18 En la actualidad 35 estados soberanos del continente forman parte de este organismo regional. 
Como uno de los principales ejemplos de esta transformación se encuentran los Acuerdos sobre Derechos y Cultura Indígena pactados entre representantes del Ejecutivo federal y del Ejército Zapatista el 16 de febrero de 1996, en el municipio de San Andrés Larráinzar, Chiapas, con el objeto de distender el conflicto armado mediante la concertación de instrumentos que atendieran los problemas estructurales (económicos, sociales, culturales y políticos) que le dieron origen.

Apoyados en el contenido de los instrumentos internacionales existentes en la materia, los denominados Acuerdos de San Andrés logran expresar con claridad la defensa de los intereses colectivos de los pueblos indígenas del país, que por años fueron articulados como demandas concretas de tierra, justicia, apoyos para la subsistencia, educación, salud $\mathrm{y}$, en general, de un acceso a condiciones de vida dignas, y al llegar a este punto encuentran su elaboración más detallada, al reconocer que, para gozar de estos derechos - que los marcos legales existentes les otorgaban en lo formal, mediante una serie de derechos civiles y políticos, ${ }^{19}$ pero que en los hechos les eran negados por su condición marginal en el ámbito nacional - era necesario primero reivindicar los derechos colectivos, como medio para lograr el ejercicio pleno de los civiles y políticos. Al respecto, cabe apuntar que es en este momento cuando los pueblos indios dan sustento al planteamiento de interdependencia de los Derechos Humanos individuales y colectivos que la ONU postula.

La importancia de los acuerdos pactados radica en la reivindicación de derechos colectivos como la autonomía y la autodeterminación, mismos que sumados a otras demandas podemos decir que

[...] representan para los pueblos indígenas del país, el instrumento a través del cual legitiman y ven reflejadas sus demandas de reconocimiento de sus derechos. En él se sientan las bases para la creación de una nueva relación entre el Estado mexicano y los pueblos indígenas, a través de la

19 A excepción del artículo 27 Constitucional que planteaba la existencia de una forma comunitaria de tenencia de la tierra (el ejido) para estas poblaciones que, sin embargo, fue afectada en su concepción original a partir de las reformas hechas en 1993. 
modificación del marco jurídico, en el cual se debería incorporar a los pueblos indígenas como sujetos colectivos de derecho y su derecho a la libre determinación expresado en autonomía, el cual permitiría a los pueblos indígenas decidir y ejercer sus formas propias de organización social, política, económica y cultural; aplicar sus sistemas normativos en la resolución de conflictos internos, garantizar el acceso a la jurisdicción del Estado tomando en cuenta sus particularidades culturales, reconocer el derecho que tienen los pueblos indígenas sobre sus tierras y territorios, así como el acceso a los recursos naturales en ellos existentes.

Por otro lado, (los acuerdos) establecen el derecho de los pueblos y comunidades indígenas para que ejerzan una participación directa en la vida política nacional, a través del reconocimiento de sus autoridades tradicionales y sus formas propias de elección; garantiza la difusión, preservación y enriquecimiento de sus conocimientos, lenguas y demás elementos constitutivos de sus culturas, así como el acceso a una educación bilingüe e intercultural que les permita su desarrollo cultural. ${ }^{20}$

Para lograr el reconocimiento jurídico de estos acuerdos se planteó la necesidad de que fueran articulados como una iniciativa de reforma constitucional, encomendándosele esta tarea a la Comisión de Concordia y Pacificación (COCOPA), derivando de su trabajo una propuesta de Ley que incorporaba el contenido del Convenio núm. 169 de la OIT y las demandas expresadas en los Acuerdos de San Andrés.

No obstante que el EZLN avaló la iniciativa final, al igual que los representantes de gran parte de los pueblos indígenas del país, en un primer momento (1996) el Gobierno Federal en turno se negó a cumplir con su compromiso previo de presentar esta propuesta al Congreso de la Unión. Constituyendo este hecho una nueva ruptura en el diálogo para resolver el conflicto en Chiapas y, en mayor medida, en la posibilidad de iniciar una nueva relación, más legítima y justa, con los descendientes de los pobladores originarios del territorio nacional.

20 Documento colectivo, "El largo camino de la Reforma Constitucional sobre Derechos y Cultura Indígena", en Francisco López Bárcenas et al., Los derechos indígenas y la reforma constitucional en México, México, Centro de Orientación y Asesoría a Pueblos Indígenas-Ce Acatl, A. C.-Casa Vieja-Red es, 2001, pp.108-109, cursivas mías. 
Tras el cambio del titular del Ejecutivo federal, la nueva administración a cargo de Vicente Fox Quesada cumplió con el compromiso político de presentar la iniciativa de la COCOPA ante el Poder Legislativo de la Nación, absteniéndose, sin embargo, de defender su propuesta frente al pleno del Congreso, con lo que ésta fue sujeta a revisiones que terminaron modificando en lo sustancial el contenido del documento inicial.

Desde las primeras negativas a reconocer los Acuerdos de San Andrés hasta las discusiones sostenidas en el Congreso de la Unión — durante la última revisión de la iniciativa de la COCOPA realizada en los primeros meses de 2001 - los principales argumentos sostenidos para obstaculizar su aprobación han ido en el sentido de cuestionar el marco de derecho resultante en caso de adoptarse esta propuesta ya que, según algunos juristas, no se puede plantear un régimen especial o de excepción para los indígenas (en este caso los derechos colectivos), cuando existe un régimen de igualdad jurídica originario (derecho individual) que, siguiendo esta lógica, llevaría a contradicciones inmediatas al tratar de equiparar "derechos de naturaleza diferente", que finalmente resultarían riesgosos para el mantenimiento del estado de derecho. ${ }^{21}$

Ante este aparente callejón sin salida, las reflexiones al respecto comprueban lo que apegándose al marco de los Derechos Humanos promovidos por la ONU es evidente: tal contradicción (en el caso de existir) no es necesariamente irresoluble, ya que, al partir de una perspectiva que incorpore la complementariedad, indivisibilidad e interdependencia con que se concibe a los derechos colectivos e individuales por las instancias internacionales, es posible plantear alternativas que, como en el caso del antiguo artículo 27 Constitucional, permitan que un orden jurídico pensado originalmente a partir de una premisa liberal, pueda ser compatible con derechos más amplios de carácter social.

${ }^{21}$ Cfr. Alejandro López Mercado, "La defensa de los derechos colectivos de los pueblos indígenas de México. Los casos del FIOB, la UCIHJ y la comunidad de Santa Ana Zirosto", Cuadernos Agrarios, Nueva Época, año 8, núm. 16, México, 1998, pp. 174-198. 
Algunas observaciones interesantes a este respecto son planteadas por Alejandro López Mercado, quien señala:

Se dice que los individuos indígenas no pueden ni deben estar sujetos a un régimen especial o de excepción, porque eso contraviene lo dispuesto por la propia Constitución y por lo tanto trastocaría el "estado de derecho" vigente, por lo que deben estar sujetos al mismo régimen que estamos sujetos el resto de la población, desconociendo y negando en los hechos y en la ley los derechos colectivos de los pueblos indígenas. Sin embargo no se toma en cuenta que si se reconocieran tales derechos, en realidad se reconocerían competencias y jurisdicciones territoriales a los pueblos indígenas, que en la práctica ya existen, y por lo tanto no se crearía un régimen especial o de excepción, sino que se estaría ante un régimen conocido y aceptado por todos los miembros que integran esos territorios, sin negar lo que son los derechos colectivos.

Al hablar del principio de igualdad jurídica no se considera que dicho principio también puede y debe aplicarse a los distintos pueblos indígenas en el sentido de que todos estos pueblos debieran considerarse iguales ante la ley, con los mismos derechos colectivos y facultades, como pueblos, independientemente de su diversidad cultural. Es decir, el principio de igualdad jurídica es aplicable también a los derechos colectivos. Derechos que $\sin$ embargo nunca han sido reconocidos. ${ }^{22}$

La anterior exposición nos lleva a plantearnos la necesidad de pensar que el paso de la consideración de los indígenas como sujetos de interés público (como actualmente establece la Constitución a partir de las reformas aprobadas en 2001), a una que les reconozca como sujetos de derechos colectivos, en ningún modo contraviene al derecho, sino que lo enriquece al formular alternativas de convivencia entre los intereses individuales y los colectivos.

Una fórmula propuesta como ejemplo de la conciliación de derechos de "naturaleza distinta", es la planteada para el reconocimiento de la libre determinación de los pueblos indígenas por Miguel Concha Malo, quien explica que este derecho podría operar en

regímenes políticos modernos de autonomías acotadas dentro de un mismo Estado nacional soberano, pluriétnico y pluricultural. Ello implicaría

${ }^{22}$ Ibid., p. 176. 
entre otras cosas el establecimiento constitucional de un pluralismo jurídico pactado, sin más límite que el respeto universal a las garantías individuales y a los Derechos Humanos universalmente reconocidos. ${ }^{23}$

$\mathrm{Al}$ igual que estas alternativas, existen abundantes trabajos que plantean fórmulas para esta compatibilidad de intereses y sujetos de derecho, que sin duda ponen en cuestión los argumentos presentados por los opositores a estos cambios jurídicos.

\section{CONCLUSIONES: ¿HACIA UN NUEVO CONFLICTO?}

Como se ha planteado a lo largo de este trabajo, la intensidad de las movilizaciones indígenas en América Latina es un elemento revelador del descontento social existente, a causa de las cada vez más menguadas condiciones de vida que enfrentan los habitantes de la región, agudizándose dramáticamente cuando además éstos son identificados como indígenas. De tal suerte, cotidianamente comprobamos la veracidad de esa idea que asocia directamente lo indígena con la miseria y la marginalidad.

Como un esfuerzo para evitar que esta situación se agudice - y principalmente como resultado de la presión ejercida por las acciones permanentes de distintos pueblos y organizaciones indígenas - algunos organismos internacionales se han dado a la tarea de promover el desarrollo de los pueblos indígenas, inscribiendo sus actividades en el marco de la lucha por los Derechos Humanos. Al respecto se han obtenido avances significativos en la creación de instrumentos internacionales que, a partir de un compromiso pactado con los Estados-participantes en esos sistemas, buscan exhortar a éstos a realizar acciones a favor del reconocimiento, la defensa y promoción de los derechos de los pueblos indígenas que forman parte de sus naciones.

23 Miguel Concha Malo, "Sujetos de derechos colectivos", en Cynthia Arnson, Raúl Benítez Manaut y Andrew Selee [eds.], Chiapas. Interpretaciones sobre la negociación y la paz, México, CISAN-UNAM, 2003, pp. 8 y 9. 
Sin embargo, como lo demuestra el caso de México, en el que no sólo el Estado desconoció un acuerdo de pacificación interno, sino también se violaron convenios internacionales adoptados y ratificados con anterioridad a la emergencia indígena en el territorio nacional, este tipo de compromisos per se no garantizan que en los hechos se registre una protección segura a los derechos colectivos de los pueblos indígenas, o que tenga lugar un mejoramiento sustantivo de sus condiciones de vida.

Sumado a esta situación, se debe tener en cuenta el hecho de que históricamente la conjugación de gran parte de estos acuerdos ha dependido de la existencia de un contexto político favorable a su adopción y ratificación por parte de los actores involucrados, elemento que en la actualidad ha registrado transformaciones importantes a causa de los nuevos procesos ocurridos en el contexto internacional (conflictos bélicos, incremento de los actos terroristas, desastres naturales) que demandan la atención prioritaria de estados y organismos internacionales en demérito de la relevancia otorgada a las cuestiones indígenas hace una década.

El panorama a futuro se aventura incierto ante la radicalización de los actores, entre quienes desde una posición de poder niegan cualquier concesión social e ignoran a los indígenas y a la población pobre en general, y aquellos que "ya no aguantan más", quienes no tienen ya nada que perder ante un orden que les niega la posibilidad misma de seguir existiendo.

En el plano global, aún se esperan las acciones que promoverán las instancias internacionales que han observado cómo el Estado mexicano ha violado los compromisos pactados, desconociendo las responsabilidades adquiridas, con el argumento de que éstas son ambiguas o porque contravienen a su derecho interno. Específicamente, en el caso de la OIT, es evidente que la reforma constitucional en materia de derechos y cultura indígena aprobada por el Congreso de la Unión en abril de 2001, no tomó en consideración las obligaciones asumidas por esta entidad jurídica al suscribir el Convenio núm. 169 elaborado 
por este organismo, por lo que el Estado podría enfrentar sanciones económicas, a causa de la omisión hecha. ${ }^{24}$

Aunada a esta responsabilidad, se encuentra el descrédito ante la opinión pública internacional de un Estado que se presume democrático, pero que, como lo señala un informe presentado por la Federación Internacional de los Derechos Humanos con relación a la reforma comentada, no es capaz de reconocer los derechos colectivos de los pueblos indígenas de su territorio. Observaciones que recientemente fueron ratificadas por el relator especial de Naciones Unidas para cuestiones indígenas, Rodolfo Stavenhagen, en su informe sobre la visita a México realizada del $1^{\circ}$ al 18 de junio de 2003, el que destaca entre sus conclusiones:

56. A pesar de una larga historia de indigenismo por parte del Estado mexicano a lo largo del siglo Xx, los rezagos acumulados entre la población indígena la colocan en una situación de franca desventaja frente al resto de la población nacional, víctima de discriminación y exclusión social, con bajos índices de desarrollo social y humano [...].

57. La reforma constitucional del 2001, producto tardío y adulterado de los Acuerdos de San Andrés firmados entre el Gobierno federal y el EZLN, reconoce formalmente el derecho a la libre determinación de los pueblos indígenas, pero lo encierra con candados que hacen difícil su aplicación en la práctica. Por ello la reforma ha sido impugnada por el movimiento indígena organizado que demanda insistentemente su revisión, como condición necesaria para lograr la paz en el país y garantizar los derechos humanos de los pueblos indígenas [...].

58. La protección de los derechos humanos de los pueblos indígenas se da en el marco de una alta y persistente conflictividad social acompañada frecuentemente de violencia, en torno a problemas agrarios, ambientales y políticos que se repiten en casi todas las regiones indígenas, mayoritariamente rurales [...].

62. [...] La actual política estatal hacia los indígenas procura lograr soluciones negociadas a los "focos rojos" conflictivos, promover y apoyar

24 Para más información sobre los acuerdos internacionales que clarifican la responsabilidad del Estado con respecto al cumplimiento de compromisos adquiridos con organismos multilaterales, véase Ximena Gallegos Toussaint, "La Reforma Constitucional en materia indígena y la responsabilidad internacional del Estado mexicano", en López Bárcenas et al., op. cit., pp. 79-93. 
actividades productivas y proveer servicios sociales diversos a las comunidades. No se aparta mayormente de la orientación que ha caracterizado al indigenismo durante más de medio siglo, pero se encuentra muy restringida por las limitaciones y los recortes al presupuesto público así como la evidencia que la problemática de los pueblos indígenas no es de alta prioridad para el Estado mexicano [...].

64. El Relator Especial recomienda al Congreso de la Unión reabrir el debate sobre la reforma constitucional en materia indígena con el objeto de establecer claramente todos los derechos fundamentales de los pueblos indígenas de acuerdo a la legislación internacional vigente y con apego a los principios firmados en los Acuerdos de San Andrés. ${ }^{25}$

Sin duda, como lo evidencia el diagnóstico del relator de Naciones Unidas, la no resolución de las causas que han dado origen a los brotes de protesta social podría acelerar el paso hacia un camino sin retorno, donde la frontera entre inconformidad y violencia se vuelva cada vez más imperceptible. Al respecto, se presenta como una tarea urgente el aprender de los principales actores involucrados en esta situación, los propios pueblos indígenas, quienes mediante múltiples medidas de hecho han ido desarrollando alternativas que más allá de las acciones de los estados y las instancias internacionales, en la práctica les han permitido ejercer sus derechos y preservar su identidad. Esta forma de resolver sus problemas no sólo precisa ser reconocida, sino que en todo caso, deberá incorporarse en las propuestas que a futuro se planteen a fin de que los conflictos en potencia puedan ser canalizados por las vías más justas de solución para todos los que se encuentren involucrados en ellos.

25 ONU, "Informe del Relator Especial sobre la situación de los derechos humanos y las libertades fundamentales de los indígenas, Rodolfo Stavenhagen, sobre su misión a México ( $1^{\circ}$ a 18 de junio de 2003)", Consejo Económico y Social/Comisión de Derechos Humanos, 23 de diciembre de 2003 (E/CN.4/2004/80/Add.2), pp. 18-20, las cursivas mías. 
BIBLIOGRAFÍA

Barié, Cletus Gregor, Pueblos indígenas y derechos constitucionales en América Latina: un panorama, México, Instituto Indigenista Interamericano, 2000.

Concha Malo, Miguel, "Sujetos de derechos colectivos", en Cynthia Arnson, Raúl Benítez Manaut y Andrew Selle [eds.], Chiapas. Interpretaciones sobre la negociación y la paz, México, CISAN-UNAM, 2003. Contreras Nieto, Miguel Ángel, El derecho al desarrollo como derecho humano, México, Comisión de Derechos Humanos del Estado de México, 2000.

Díaz Polanco, Héctor, Autonomía regional. La autodeterminación de los pueblos indios, México, Siglo XXI/UnAM, 1991.

LÓPEZ BÁRCENAS, FRANCISCO et al., Los derechos indígenas y la reforma constitucional en México, México, Centro de Orientación y Asesoría a Pueblos Indígenas-Ce Acatl, A. C.-Casa Vieja-Redes, 2001. Autonomías y derechos indígenas en México, México, CONACULTACentro de Orientación y Asesoría a Pueblos Indígenas, 2002.

López Mercado, Alejandro, "La defensa de los derechos colectivos de los pueblos indígenas en México. Los casos de FIOB, la UCIHJ y la comunidad de Santa Ana Zirosto", Cuadernos Agrarios, Nueva Época, año 8, núm. 16, México, 1998.

LÓPEZ Y RIVAs, GILBERTO, Nación y pueblos indios en el neoliberalismo, México, UiA/Plaza y Valdés, 1995.

ONU, "Informe del Relator Especial sobre la situación de los derechos humanos y las libertades fundamentales de los indígenas, Rodolfo Stavenhagen, sobre su misión a México ( $1^{\circ}$ a 18 de junio de 2003)", Consejo Económico y Social/Comisión de Derechos Humanos, 23 de diciembre de 2003 (E/CN.4/2004/80/Add.2).

SANDOVAl TERÁn, ARELI, Los derechos económicos, sociales y culturales. Una revisión del contenido esencial de cada derecho y de las obligaciones del Estado, México, DECA Equipo Pueblo, A. C.-Asociación Latinoamericana de Organizaciones de Promoción, 2001. 
ISABEL DE LA RoSA QUIÑONES

Stavenhagen, Rodolfo, "El marco internacional del Derecho Indígena", en Magdalena Gómez [coord.], Derecho indígena, México, INIAMNU, 1997.

, Derecho indígena y derechos humanos en América Latina, México, COLMEX-IIDH, 1988. 